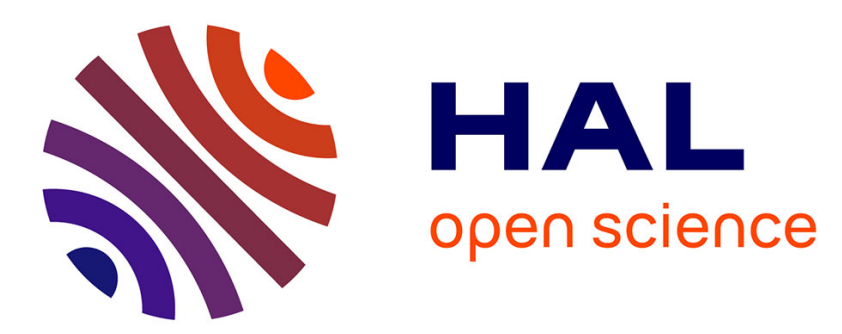

\title{
Ethical and Social Considerations for the Introduction of Human-Centered Technologies at Work
}

\author{
Pauline Maurice, Ludivine Allienne, Adrien Malaisé, Serena Ivaldi
}

\section{To cite this version:}

Pauline Maurice, Ludivine Allienne, Adrien Malaisé, Serena Ivaldi. Ethical and Social Considerations for the Introduction of Human-Centered Technologies at Work. IEEE Workshop on Advanced Robotics and its Social Impacts (ARSO), 2018, Genova, Italy. hal-01826487

\section{HAL Id: hal-01826487 \\ https://hal.science/hal-01826487}

Submitted on 29 Jun 2018

HAL is a multi-disciplinary open access archive for the deposit and dissemination of scientific research documents, whether they are published or not. The documents may come from teaching and research institutions in France or abroad, or from public or private research centers.
L'archive ouverte pluridisciplinaire HAL, est destinée au dépôt et à la diffusion de documents scientifiques de niveau recherche, publiés ou non, émanant des établissements d'enseignement et de recherche français ou étrangers, des laboratoires publics ou privés. 


\title{
Ethical and Social Considerations for the Introduction of Human-Centered Technologies at Work
}

\author{
Pauline Maurice $^{1}$, Ludivine Allienne ${ }^{2}$, Adrien Malaisé ${ }^{1}$, Serena Ivaldi ${ }^{1}$
}

\begin{abstract}
Human-centered technologies such as collaborative robots, exoskeletons, and wearable sensors are rapidly spreading in industry and manufacturing because of their intrinsic potential at assisting workers and improving their working conditions. The deployment of these technologies, albeit inevitable, poses several ethical and societal issues. Guidelines for ethically aligned design of autonomous and intelligent systems do exist, however we argue that ethical recommendations must necessarily be complemented by an analysis of the social impact of these technologies. In this paper, we report on our preliminary studies on the opinion of factory workers and of people outside this environment on humancentered technologies at work. In light of these studies, we discuss ethical and social considerations for deploying these technologies in a way that improves acceptance.
\end{abstract}

\section{INTRODUCTION}

In recent years, interest for human-centered assistive technologies has spread rapidly in manufacturing and industry, from bimanual cooperation in assembly with collaborative robotic manipulators to physical assistance with exoskeletons [1], [2], [3]. This enthusiasm is explained by the potential these technologies have to address the growing problem of work-related musculoskeletal disorders (MDSs) by reducing workers exposure to biomechanical MSDs risk factors [4], [5], [6]. Wearable sensors that monitor a person's physical state are another promising technology which may help decrease the prevalence of MSDs [7], [8].

These applications have driven research in many fundamental topics, such as adaptative role allocation during collaboration [9], control of contacts and physical interaction [10], learning by demonstration [11], safe control [12]. Specifically, safety issues have received a great deal of attention, both in research and in standardization [13], [12], [14], [15]. For instance, ISO/TS 15066:2016 specifies safety requirements for collaborative industrial robots [16]. All these state-of-the-art advances and legal recommendations contribute to the success of the so-called Industry 4.0.

However, guaranteeing physical safety is not sufficient to ensure a smooth and successful deployment of humancentered assistive technologies in workplaces. Specific attention should also be paid to ethical and social aspects, in particular to technology acceptance. Ill-adapted technologies that have not been thought for and with their end-users may end up not being used. Worse, their use could generate additional stress, hence defeating their initial purpose of improving working conditions.

\footnotetext{
${ }^{1}$ Inria, Université de Lorraine, CNRS, LORIA, F-54000 Nancy, France name.surnamedinria.fr

${ }^{2}$ Université Picardie Jules Verne, CURAPP-ESS, France
}

The research and development of collaborative robotics technologies raises ethical issues [17], [18]. At hardware level, developing wearable and physically interacting technologies raises several concerns for the safety and certification of the devices [1], [19]. At software level, the manipulation of data, their transmission, processing, and eventually the decisions computed by AI algorithms [20] raise concerns about privacy, security, and liability [21].

Several working groups at national and international level have started to formalize ethical requirements for humancentered technologies (e.g. CERNA in France [22], IEEE [23]). However, they only proposed general recommendations, covering topics from system security and accountability to data ownership and user empowerment. But no proper standards have been established so far. Ethical guidelines for various applications of robotics technologies have also been proposed [24], [25], [26]. However these studies do not specifically target industrial use of robotic systems physically interacting with humans. We argue that though necessary, general ethical recommendations alone are not sufficient, as pointed out by Villani et al.[27]. They should be presented together with an analysis of the attitude of potential endusers towards these human-centered technologies. Such an analysis may shed light on the items that are most critical for the acceptance and adoption of these technologies. Indeed, technology acceptance models highlight the influence of psychosocial factors - such as social influence, image, and perceived usefulness - on the intention to use and user behavior [28]. Some recent studies about intelligent systems also used end-users attitude studies: for example, the MATE system was evaluated with a technology questionnaire [27], while Schmidtler et al. designed a questionnaire for evaluating physically assistive devices that considers the emotions and attitude of the final users [29]. This approach mixing objective and subjective measures is also adopted for the evaluation of the human-centered technologies of the AnDy project [30]. In AnDy we focus on collaborative robots, exoskeletons, and wearable sensing technologies, which are being or will be introduced in factories. For a successful adoption, it is important to assess the attitude of the potential end-users towards these technologies.

The study presented in this paper aims at assessing the opinion of non-roboticists on human-centered assistive technologies that might soon be introduced in workplaces. Three assistive technologies are targeted: collaborative robots, exoskeletons, and wearable sensors. Collaborative robots and exoskeletons directly help a human operator performing a task, either by providing physical assistance or by acting 
as a partner and performing part of the task [1], [2], [3]. Conversely, wearable sensors can provide feedback about the physical or physiological state of the operator to help her/him identify dangerous situations [7], [8]. Despite their different modes of action, these systems share a common goal: improving health at work. The main goal of the study is to identify expectations, concerns or fears raised by these three technologies. This information can then be used to provide ethical and social recommendations for the design and deployment of such technologies in workplaces, to facilitate their acceptance.

The paper is organized as follows. Section II describes the methods that were used to evaluate the attitude of different categories of people towards the three technologies mentioned previously. Section III presents the opinions and arguments of each category of people on each of the three technologies. These results are discussed in Section IV. Finally, Section V summarizes the main ethical recommendations and guidelines for an ethically guided design of humancentered technologies that include the recommendations issued by our study.

\section{METHOD}

The attitude of non-roboticists towards collaborative robots, exoskeletons and wearable sensors was assessed through semi-directed interviews and focus groups.

Semi-directed interviews are semi-structured individual interviews where the interviewer follows a pre-determined set of questions to prompt the discussion, with the possibility to explore more in depth some answers or particular themes. A list of open questions defines the general orientation of the discussion and the specific topics that need to be discussed. However, the interviewer can decide to add or remove some questions, or to change the order of the questions, depending on the answers given by the participant. Unlike a questionnaire with yes/no answers, a semi-directed interview enables participants to explain their ideas with their own words, thereby expressing more detailed opinions and providing more background to understand the motivations for their attitudes and opinions.

A focus group is a discussion in a small group (usually from four to a dozen participants maximum) on a specific topic, moderated by one or several interviewers. The goal of a focus group is to study the reactions and attitudes of the participants on the discussed topic, collecting their diverse opinions. This mode of investigation is preferred to questionnaires to leave participants more freedom in expressing their attitudes and concerns towards the specific topic, with the potential to address issues that are not foreseen by the investigators.

Two groups of participants with different backgrounds were interviewed. One group consisted of "non-workers", i.e. people who did not and had not worked in a factory. The second group consisted of factory workers, who might become end-users of the discussed technologies. Details on the participants and the interview process are given hereafter.

\section{A. Non-workers}

The attitude of non-workers towards the three technologies was assessed through a focus group discussion that took place at Inria in Nancy, France.

1) Participants: Six participants ${ }^{1}$ voluntarily took part in the focus group. The participants were 3 males and 3 females aged $50.3 \pm 8.6$ years old. They all had achieved at least 4 years of higher education. They were not factory workers, nor were they working in a field related to robotics or new technologies. The participants were recruited via an announcement on a mailing-list of the University of Lorraine. They gave written informed consent before starting the discussion, and the experimental protocol was approved by Inria's ethical committee (COERLE).

2) Focus Group: The focus group on the use of robotic technologies at work was divided in three parts. The first part of the discussion was about collaborative robots, the second part about exoskeletons, and the third part about wearable sensors. Each topic started with two questions: "What does the word collaborative robot/exoskeleton/wearable sensor evoke for you?" and "Have you ever used a collaborative robot/exoskeleton/wearable sensors? What is your experience?" Participants then watched a short video of the system discussed ${ }^{2}$. After watching the video, participants were asked "Which applications do you envision for this robot/exoskeleton/sensors? What could be the advantages and drawbacks?" Simultaneous to this question, a photo of a collaborative robot/exoskeleton/wearable sensors was displayed (Fig. 1). Though the questions were not directed towards specific domains of application, the photos and videos all pictured industrial environments which might have influenced the participants' answers.

The focus group, which lasted 2.5 hours, was moderated by two experimenters and was videotaped. The discussion was in French, the native language of all the participants.

\section{B. Factory Workers}

The attitude of factory workers towards collaborative robots, exoskeletons and wearable sensors was assessed through a focus group discussion and individual interviews conducted in the factory.

1) Participants: Four assembly lines workers in an automotive parts company voluntarily took part in the focus group and the interviews ${ }^{3}$. The participants were 2 males and 2 females aged 20,22, 40, and 49 years old. Two of them had been working in the factory for more than 10 years, and the two others for less than 1 year. The participants were recruited by the occupational health team of

\footnotetext{
${ }^{1}$ For this kind of focus group studies, the recommended number of participants is usually between five and eight. Six is a good choice if the group is gender-balanced like in this case.

${ }^{2}$ Video of collaborative robot: https://www.youtube. $\mathrm{com} /$ watch? $\mathrm{v}=$ i9Vbh2mPG6M. Video of exoskeleton: https: //www. youtube.com/watch?v=lAD039zu5jw. Video of wearable sensors: https: / / www . youtube. com/watch?v=E90T9pkZMgk

${ }^{3}$ Four is a minimum size for a focus group: however, recruiting factory workers for this kind of studies is very difficult, as they need the approval from their managers to participate during their working hours.
} 

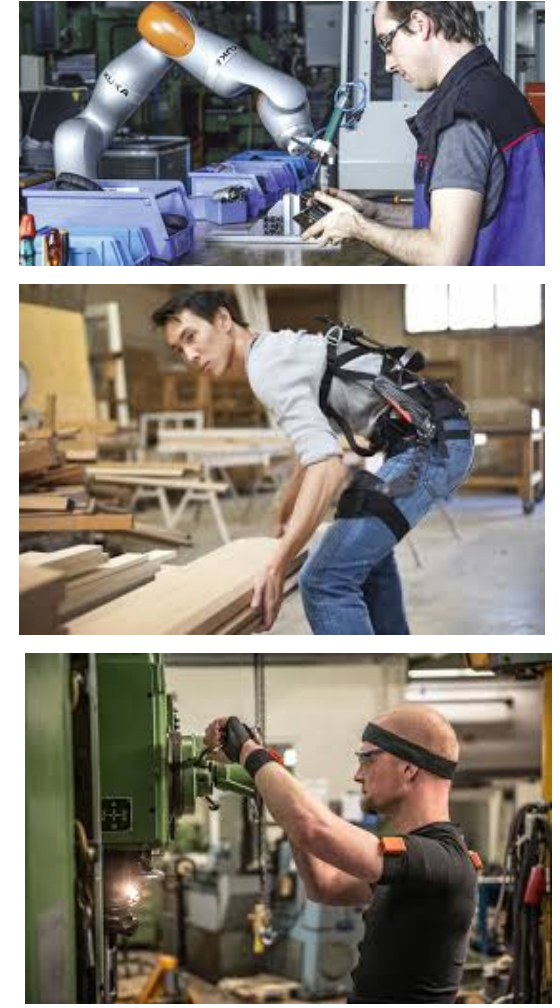

Fig. 1. Photos of a collaborative robot (top), an exoskeleton (center) and wearable sensors (bottom) shown to the participants in the two focus groups, with factory workers and with non-workers.

the company. The participants gave written informed consent before starting the discussion, and the protocol was approved by Inria's ethical committee.

2) Focus Group: The organization of the focus group was similar to the focus group conducted with non-workers (same questions, same videos). The focus group with factory workers lasted 1 hour and 10 minutes and was videotaped. The four workers were present, plus two interviewers and two members of the occupational safety and health team of the company. These two persons did not actively take part in the discussion. Specific attention was paid to equally sharing speaking time among the workers.

3) Interviews: After the focus group, semi-directed interviews were conducted with the four workers. These individual interviews gave the interviewers the opportunity to clarify some ideas that were expressed during the focus group and discover new elements behind the opinions of the participants.

During the interview, participants first introduced themselves with background information such as job description and years of experience in the company. They were asked about present or past experience in working with machines or robots, associated feelings, and changes that such machines induced in their work. The discussion then focused on how participants envisioned the introduction and use of collaborative robots and exoskeletons in their work. Next, participants were asked about their opinion and envisioned conditions of use of wearable sensors at work. The discussion ended on the frequency and ease of use of new technologies in daily life.

Each interview lasted 15 to 20 minutes and was videotaped. The discussion was in French, which is the native language of all the participants. Only the interviewed worker and the two interviewers were present.

\section{Data Analysis}

The recordings of the two focus groups and the four interviews were transcribed into text to facilitate the analysis. For each participant and each technology all the arguments cited or acknowledged by the participant during the discussion were listed and classified into three categories: pros, cons, and condition of use. Since all participants expressed both pros and cons arguments, a participant's global opinion (positive or negative) was defined by the ratio between the number of pros and cons expressed by the participant over the course of the whole discussion. The reactions previous to watching the videos were not taken into account in the analysis because most participants had no idea what each technology was referring to (especially collaborative robots).

\section{RESULTS}

The main arguments in favor and against the use of collaborative robots, exoskeletons and wearable sensors at work are summarized in Table I, II and III respectively. The opinion of factory workers and of non-workers on the three technologies and the conditions of use they envisioned are detailed hereafter.

\section{A. Collaborative Robots}

1) Opinion: Among the six participants in the nonworkers group, three had a positive opinion on the use of collaborative robots in factories, while the three others had a negative opinion. A similar trend was observed among factory workers, though with slightly more positive opinions. Out of four workers, one was very positive about the idea of using collaborative robots in his/her job, two were rather positive and one was against it.

Several of the pro-robot arguments were common to non-workers and factory workers (see Table I). The direct benefit for the company in the form of increased productivity was cited as a major advantage in both groups. The other pros were all related to employees' well-being at work. Non-workers focused on the psycho-social well-being only. Conversely, factory workers also cited the physical benefit that a collaborative robot could provide, both directly by reducing efforts, and indirectly by leaving workers more time to execute movements in an ergonomic way.

Unsurprisingly, the most cited against-robot argument the same in both groups - was the job loss caused by replacement of employees by robots. Then, as for pro-robot arguments, non-workers focused on the psycho-social consequences. They insisted on the stress that may be induced by reduced job control and absence of human dimension when working with a robotic partner. Reduced job control was also cited by factory workers with the fear of losing 
the human "added-value" or expertise. But factory workers also expressed more pragmatic concerns, like consequences of a robot breakdown. On the contrary, the last concern of non-workers was related to AI fantasy.

2) Envisioned Conditions of Use: According to participants, a collaborative robot should only perform tasks with no added-value that are considered boring by humans. In particular, participants thought such robots could be useful to relieve workers in tasks with strong physical demands. For instance, a collaborative robot could pick up and position a heavy piece on which the human could then work (e.g. assembly, visual inspection).

Importantly, participants requested that a collaborative robot could be easily configured for - and by - each user individually. In particular, the possibility to adapt the robot's work pace to the human's current work pace, either manually or automatically, was a strong demand. However, factory workers did not want too much adaptation either. The robot's behavior should remain predictable and repeatable because workers often perform their gestures automatically without thinking. If the robot changes its behavior continuously, then workers waste time by re-planning a new gesture every time and adapting to the robot.

\section{B. Exoskeletons}

1) Opinion: The general attitude towards exoskeletons was more positive than the one towards collaborative robots, especially among factory workers: all four were positive about using exoskeletons in their job. In the non-workers group, the opinions were mixed but with a dominant positive trend: three participants had a positive opinion on exoskeletons, two had a mixed opinion and one had a mostly negative opinion.

For both groups, the main advantage of exoskeletons was the improvement of employees' physical capacities and wellbeing (see Table II). In addition, factory workers liked the fact that with exoskeletons the user could keep full control of the gesture. They saw it as positive from a psychosocial standpoint - employees do not experience a reduction in job control - and from a technical standpoint - employees can continue working if the system breaks down. These two advantages were presented in opposition to drawbacks of collaborative robots.

Unlike positive arguments, negative arguments were entirely different in both groups. Non-workers were concerned by the threat exoskeletons might cause to the users' physical safety and integrity. Such a threat could come from the system's design (movements restriction can prevent the user to avoid a dangerous situation such as a fall), its overuse (muscular atrophy leading to physical dependency) or a malevolent act (malware or electronic virus by which a thirdparty takes control of the exoskeleton). Conversely, factory workers seemed to trust exoskeletons regarding safety. They were only concerned about the comfort.

2) Envisioned Conditions of Use: Interestingly, participants did not think of an exoskeleton as a robot, but as an equipment to help and protect them. In particular, they thought an exoskeleton could protect their back when carrying heavy loads. However, they insisted on the fact that its use should remain intermittent; it should not be/have to be worn all day long. In addition, the exoskeleton should only follow, and never lead or force the movement.

\section{Wearable Sensors}

1) Opinion: The attitude towards wearable sensors was almost uniformly positive in both groups, except for one participant. The four factory workers and five of the nonworkers were positive about using wearable sensors at work. Only the last participant in the non-workers group was rather negative about the use of wearable sensors.

Both groups used similar arguments in favor of wearable sensors, focusing on the physical benefit for workers (see Table III). Workers and non-workers thought of such sensors as an efficient way to decrease the risk of developing musculo-skeletal disorders, both directly by signaling bad movements, and indirectly by providing data for improvement of workstations. Non-workers additionally mentioned the self-assessment as a psycho-social advantage.

Similarly to exoskeletons, factory workers' concerns were more pragmatic than non-workers' concerns. Non-workers were worried about the psychological pressure, either selfimposed or from the management, that the use of such a system might cause. On the other hand, factory workers only raised the issue of the comfort of a wearable system (e.g., weight, temperature).

2) Envisioned Conditions of Use: Participants agreed that wearable sensors would be an efficient training tool to learn/re-learn ergonomic movements. They thought of such a system as a medical device for prevention, diagnosis and/or treatment of work-related health issues. However, like for exoskeletons, they requested that the system be used only temporarily (e.g. for a training period) and voluntarily.

\section{DISCUSSION}

The interviews of non-workers and factory workers revealed that both groups have a rather positive opinion on the use of human-centered assistive technologies at work. All participants thought each of the three technologies could be beneficial for the physical well-being of workers, and could help reduce the risk of developing MSDs. Yet, concerns were raised, which need to be addressed to avoid stress and refusal when deploying these systems in workplaces. Importantly, these concerns varied between groups and technologies. These differences and their implications are discussed hereafter.

\section{A. Workers vs. Non-workers: Pragmatism vs. Fantasy}

In their arguments in favor and against the use of collaborative robots, exoskeletons and wearable sensors, factory workers focused essentially on practical aspects. For instance, the only concerns they had about exoskeletons and wearable sensors were comfort issues. Conversely, nonworkers were more concerned about security (data protection, electronic virus). Similar trends were observed in the 


\begin{tabular}{|c|c|c|}
\hline & Non-workers & Factory workers \\
\hline$\stackrel{0}{0}$ & $\begin{array}{l}\text { - Work is done faster with a robot that performs part of the } \\
\text { task, hence increased productivity. } \\
\text { - A robot facilitates work during repetitive tasks, hence } \\
\text { reduced stress. } \\
\text { - A robot offloads workers from boring tasks. }\end{array}$ & $\begin{array}{l}\text { - Work is done faster with a robot that performs part of the } \\
\text { task, hence increased productivity. } \\
\text { - A robot that performs part of the task leaves workers more } \\
\text { time to better execute their part of the work. } \\
\text { - A robot offloads workers from boring tasks. } \\
\text { - A robot reduces the physical demand on workers. }\end{array}$ \\
\hline$\tilde{\tilde{\theta}}$ & $\begin{array}{l}\text { - Collaborative robots are a first step towards full automation: } \\
\text { fear of job loss. } \\
\text { - Workers do not have direct control over the robot's work } \\
\text { yet they are responsible for the work done, hence increased } \\
\text { stress. } \\
\text { - A robotic partner cannot identify and signal or compensate } \\
\text { for error or failure, hence increased stress. } \\
\text { - Discussion and empathy cannot be used with a robot. } \\
\text { - A robot that can adapt and learn from experience may } \\
\text { become too intelligent and unpredictable: fear of AI. }\end{array}$ & $\begin{array}{l}\text { - Collaborative robots are a first step towards full automation: } \\
\text { fear of job loss. } \\
\text { - Workers do not want to delegate their technical gesture to } \\
\text { a robot. } \\
\text { - Work cannot be continued if the robot breaks down. }\end{array}$ \\
\hline
\end{tabular}

TABLE I

MAIN ARGUMENTS IN FAVOR AND AGAINST THE USE OF COLLABORATIVE ROBOTS IN FACTORIES CITED BY PARTICIPANTS IN THE NON-WORKERS GROUP (LEFT COLUMN) AND IN THE FACTORY WORKERS GROUP (RIGHT COLUMN).

\begin{tabular}{ll}
\hline Non-workers & Factory workers \\
\hline $\begin{array}{l}\text { - An exoskeletons alleviates the physical load on workers. } \\
\text { an exoskeleton enhances human physical abilities, e.g. } \\
\text { augments force production, helps a paralyzed person move. }\end{array}$ & $\begin{array}{l}\text { - An exoskeleton alleviates the physical load on workers. } \\
\text { With a exoskeleton, the human remains in full control of } \\
\text { the technical gesture. }\end{array}$ \\
$\begin{array}{l}\text { - Work can be continued if the exoskeleton breaks down. } \\
\text { - An exoskeleton can be hacked, causing a loss of control over } \\
\text { one's own body. }\end{array}$ & $\begin{array}{l}\text { - Wearing an exoskeleton on one's body for several hours } \\
\text { may be uncomfortable (weight, temperature) }\end{array}$ \\
$\begin{array}{l}\text { - An exoskeleton may prevent certain movements. } \\
\text { - Prolonged use of an exoskeleton may cause muscular atrophy. }\end{array}$ \\
\hline
\end{tabular}

TABLE II

MAIN ARGUMENTS IN FAVOR AND AGAINST EXOSKELETONS CITED BY PARTICIPANTS IN THE NON-WORKERS GROUP (LEFT COLUMN) AND IN THE FACTORY WORKERS GROUP (RIGHT COLUMN).

\begin{tabular}{ll}
\hline Non-workers & Factory workers \\
\hline $\begin{array}{l}\text { Wearable sensors help correct one's posture, hence reducing } \\
\text { MSDs risks. }\end{array}$ & $\begin{array}{l}\text { - Wearable sensors help learn the ergonomic way to perform } \\
\text { a movement, hence reducing MSDs risks. }\end{array}$ \\
$\begin{array}{l}\text { - Wearable sensors enable self-assessment and self-correction } \\
\text { without a third party judgment. }\end{array}$ & $\begin{array}{l}\text { Wearable sensors enable online self-assessment and self- } \\
\text { correction of movements. }\end{array}$ \\
$\begin{array}{l}\text { - Wearable sensors provide information to improve } \\
\text { workstations design. }\end{array}$ & $\begin{array}{l}\text { Wearable sensors provide information to improve } \\
\text { workstations design. }\end{array}$ \\
$\begin{array}{ll}\text { - Wearable sensors provide user-specific information. } \\
\text { - Data might be used to track employees' productivity, hence } \\
\text { confidentiality issue. }\end{array}$ & $\begin{array}{l}\text { - Wearing sensors on one's body may be uncomfortable } \\
\text { (weight, temperature) }\end{array}$ \\
$\begin{array}{l}\text { Permanent assessment can cause guilt if workers do not want } \\
\text { or cannot follow the system's recommendations. }\end{array}$ & $\begin{array}{l}\text { Performing movements in an ergonomic way takes too } \\
\text { much time, hence the information provided by wearable } \\
\text { sensors is useless. }\end{array}$ \\
\hline $\begin{array}{l}\text { - Workers may be forced to use wearable sensors against their } \\
\text { will by legal or social pressure. }\end{array}$ & \\
\hline
\end{tabular}

TABLE III

MAIN ARGUMENTS IN FAVOR AND AGAINST THE USE OF WEARABLE SENSORS AT WORK CITED BY PARTICIPANTS IN THE NON-WORKERS GROUP (LEFT COLUMN) AND IN THE FACTORY WORKERS GROUP (RIGHT COLUMN). 
first part of the discussion, when participants were asked what each technology evoked for them (before watching the videos). Factory workers related collaborative robots to the machines they see everyday in their assembly lines, whereas non-workers talked about software and artificial intelligence.

These differences are explained by the background and experience of both groups. Factory workers are used to working with robots and machines, so they have a concrete idea of what a robot is and can do. They also tend to be more positive and trustful towards these technologies, because they can directly benefit from them. Their work being physically strenuous, they are eager to try a system that can relieve them and they tend to see advantages more than possible drawbacks or dangers. On the other hand, non-workers had no experience with robots. Thus they relied on and were influenced by images conveyed by media and fictions (one participant cited the Terminator movie).

Whether they come from fiction or high expectations, irrational fears and false hopes may both hinder the deployment of new technologies. In particular, the general public opinions impact the "social influence" factor in technology acceptance models [28]. Therefore, the research community should engage in education and awareness activities regarding human-centered robotic technologies, both for workers and for the general public. On the other hand, the apparent absence of security and confidentiality concerns from workers should be handled carefully. Slides or misuses might cause psychological or social stress or damages. A legal framework should therefore be established to guarantee the transparency and fairness of use of sensors, exoskeletons and robots and of the data collected thereby. Interestingly, our observations are in line with those of [27] where the authors noted that "the impact on data protection was rated surprisingly low".

\section{B. Collaborative Robots vs. Exoskeleton: Rival vs. Equip-} ment

Collaborative robots and exoskeletons are two systems that can provide physical assistance to relieve workers in strenuous tasks. Yet both workers and non-workers are more positive towards exoskeletons than towards collaborative robots. Collaborative robots are perceived as potential rivals, because they take part of the technical gesture away from humans. Conversely, exoskeletons are classified as protective equipment and not as robots, because they do not act on their own but only follow the user's movements. This is somehow coherent with our observations about the mistrust towards robots when people must share decisions with them: robots taking decisions are often perceived as antagonists, even in explicit collaborative scenarios [31].

This difference can be explained by the desire to keep some "human added value" in one's job. If the technical gesture is shared with a robot, workers lose part of their added value and feel less useful. This desire to keep doing the full gesture was very prominent with one of the factory workers who was a former carpenter, hence used to creating things with his hands. The ability with the hands, the gestures and manipulations, are the human contribution to the work in terms of "intelligence". This human added value - the fact that humans can do things that robots cannot - is one of the main reasons that currently prevent robots from fully replacing humans. Sharing the technical gesture therefore raises the specter of full automation [32].

In addition, the need to feel useful and in control at work has psychological as well as physical consequences. It has been shown that job dissatisfaction and reduced job control are psychosocial factors of stress that increase the risk of developing MSDs [5], [6], [4]. Since a major goal of deploying collaborative robots in factories is to reduce exposure to biomechanical MSDs factors (high efforts and awkward postures), care should be taken to avoid increasing psycho-social factors instead. Therefore, collaborative robots should only be used for strenuous tasks with no added value.

\section{Robotic Assistance: Relief or Pressure?}

The question of time pressure at work was recurrent in the discussions, especially with factory workers who are directly exposed to it. Workers explained that they cannot execute their movements ergonomically, otherwise they are too slow and cannot keep the rhythm imposed by the tasks. They were also concerned about having to stop the assembly line if the assistive technology breaks down. In both cases, the issue was not reaching the imposed quotas and having to work overtime.

Technologies that may help matching such strong temporal demand, either by offloading workers of part of the gesture or by allowing gestures to be performed faster, are therefore perceived positively. However, this advantage should not be turned into a threat. As pointed out in the envisioned conditions of use of collaborative robots, the work pace should be controlled by the worker, and not dictated by a robot. First, because workers need to be able to adapt and slow down if they feel fatigue, reducing the direct risk of injury. Second, giving control of the work pace to the robot results in reducing the worker's job control. And reduced job control, in particular associated with a strong temporal demand, increases psycho-social stress and MSDs risks, hence defeating the purpose of the robot [5], [6], [4]. Therefore, assistive technologies should be designed in a way that avoids or minimizes reduction in job control.

A further risk is the so-called "mental" loss of control, which refers to the fact that final end-users may not be really voluntary users of these technologies. The working environment or social pressure may implicitly push workers to adopt a technology even if its use is not mandatory. Workers mentioned that they would agree to use an exoskeleton or wearable sensors "sometimes", "temporarily", or "for a few days", but they were against a permanent use. While episodic use could be acceptable if aiming at improving workers' gestures for a specific workstation, continuous use might be interpreted as a way to monitor workers' performance. This of course contradicts the initial purpose of equipping some workstations with exoskeletons as a permanent solution to alleviate the physical stress of the worker. This issue was also 
noted in [27]: "one of the biggest drawbacks of using MATE systems in industrial applications is the risk of stigmatization that could arise from the use of a system that measures a workers skills and perfor mance. This may be a sensitive issue for the worker, who may feel embarrassment from the assessment, and for his or her supervisor or employer. Although this risk is partly mitigated by precautions put in place for protecting data, care must be taken when considering MATE approaches.".

\section{GUIDELINES FOR ETHICS DESIGN OF HUMAN-CENTERED TECHNOLOGIES}

In the previous sections, we presented our study to probe into the attitude of workers and general public towards collaborative robots, exoskeletons and wearable sensors. We highlighted several issues, in particular the differences in opinions of workers and of the general public.

The outcome of our study provides complementary elements to the general ethics recommendations and guidelines that have been outlined in the last few years (e.g., [22], [23]). These general ethics guideline are a good start, but being generic they are not sufficient in some cases. Attention should be paid to the specific technologies, their use, and their end-users. We hereby summarize the main ethics guidelines and requirements for the human-centered assistive technologies addressed in this paper, and complement them with recommendations that we directly retrieved from our user study.

1) Ensure that the system does not infringe human rights: This recommendation applies both to hardware and software. Regarding hardware, the design should be such that the wearable device can be used by both men and women. For instance, in exoskeleton design, attention should be paid to forces applied on the chest. Regarding software, the main concern is to ensure that algorithms are not biased towards groups or races. If data-driven models are used, particular care should be devoted to creating and using unbiased databases. For example, having both male and female participants, with different anthropomorphic structures. Analysis should take into account individual differences, and provide models that respect such differences, i.e. that do not privilege one group.

2) The system should be accountable: Collaborative robotics systems must make real-time decisions about their actions and interactions with humans. As such, decisions taken by software algorithms should be accountable. This requires an excellent level of documentation on interconnected modules, and a thorough logging system. The use of black-box components should always be justified and documented (e.g. what does the black-box component do? What are its limits? Is it strictly necessary? Why isn't a model-based module used in that case?). The use of learning algorithms should be justified and documented. In particular learning models should be used only if they guarantee better performances than model-based approaches. Their limits should be made explicit to users. Stakeholders and final endusers should be the evaluators of the technologies, and their feedback should be taken into account in the definition of rules, guidelines and means of use of these technologies.

3) The system should be safe and transparent: The primary requirement for a system collaborating with human is to be safe. Safety of the device can be certified, but to ensure safety, rules and working conditions should always be clear to the users. Therefore an adequate education to the use of the technologies should be provided beforehand. In particular, users should have the possibility and knowledge to "diagnose" the system and understand what happens/ed, in normal mode as well as in case of malfunctioning: the system should be transparent to users in the way it works. Users should not be deprived of their choice and intelligence when using these systems, but at the same time the system should be verifiable, and its operations, computations and data traceable. Depending on the type of application and technologies, there should be clear rules for defining the level of cooperation between humans and systems when taking decisions: for example, for a robotic system it may be acceptable in some cases to be fully autonomous, in some conditions to be operated in a shared control mode, and to be fully operated by a human if there is a critical situation or safety risk that requires the human decision (especially for liability issues). This is a common example for autonomous cars, but applies to industrial robots as well. As an ultimate safety measure, a "killer switch" function or physical button turning on/off the device should be implemented. But even this extreme measure should be weighted against the possibility to implement adaptive shared control and decisionmaking strategies.

Incidentally, the recent European General Data Protection Regulation (GDPR), which applies to any business/system that processes personal data by automated or manual processing, not only specifies that humans must be informed about the logic, significance and consequences of the decision taken by automated decision-making systems, but have the right to review and contest automated decisions [33].

Transparency must also be implemented at the level of the data collected by the system. Users should be empowered of their data. Data that appear trivial to share should not be used to make inferences that an individual would not share. Users should always give their explicit informed consent before using the device and allowing retrieving their data. They should also be aware of which operations are going to be done with their data, and who is going to access the data.

4) Researchers and developers must strive to minimize the risk of misuse of the technologies: The risk of misuse may be one of the most critical issues for researchers and technology developers. On one hand, misinterpretation in media could hinder the development and deployment of human-centered technologies. On the other hand it could give false hopes and mystification. The main action for researchers is to engage in education and awareness activities regarding collaborative robotics technologies, covering all topics from hardware devices, to software, control and machine learning. The limits, pros and cons of collaborative robotics systems should be made clear to the general public and to end-users, as 
technological changes may happen very fast.

\section{CONCLUSION}

In this study, we examined the opinion of factory workers and non-workers on three human-centered technologies aiming at improving working conditions: collaborative robots, exoskeletons and wearable sensors. Workers and nonworkers were mostly positive about these technologies and agreed they would increase workers physical well-being. However, if the physical benefit provided by these technologies was not questioned, concerns about their psychological effects on workers were raised. Specifically, reduction in job control in its various forms was cited repeatedly by participants in both groups. Though preliminary, this study was necessary to provide further guidelines and recommendations for an ethically aligned design of these technologies.

In the future, we plan more interviews with workers to provide further recommendations about how to ethically deploy these technologies in factories, in an attempt to minimize the psychosocial MSDs risk factors such as stress and loss of job control.

\section{ACKNOWLEDGMENT}

This work was supported by the European Union's Horizon 2020 Research and Innovation Programme under Grant Agreement No. 731540 H2020-ICT-2016-1 (project AnDy).

\section{REFERENCES}

[1] P. Akella, M. Peshkin, E. Colgate, W. Wannasuphoprasit, N. Nagesh, J. Wells, S. Holland, T. Pearson, and B. Peacock, "Cobots for the automobile assembly line," in Proc. IEEE International Conference on Robotics and Automation (ICRA), vol. 1, 1999, pp. 728-733 vol.1.

[2] J. Schmidtler, V. Knott, C. Hölzel, and K. Bengler, "Human centered assistance applications for the working environment of the future," Occupational Ergonomics, vol. 12, no. 3, 2015, pp. 83-95.

[3] M. P. de Looze, T. Bosch, F. Krause, K. S. Stadler, and L. W. OSullivan, "Exoskeletons for industrial application and their potential effects on physical work load," Ergonomics, vol. 59, no. 5, 2016, pp. 671-681.

[4] V. Putz-Anderson, B. P. Bernard, S. E. Burt, L. L. Cole, C. FairfieldEstill, L. J. Fine, K. A. Grant, C. Gjessing, L. Jenkins, J. J. Hurrell Jr et al., "Musculoskeletal disorders and workplace factors," National Institute for Occupational Safety and Health (NIOSH), vol. 104, 1997.

[5] E. Schneider, X. Irastorza, M. Bakhuys Roozeboom, and I. Houtman, "Osh in figures: occupational safety and health in the transport sectoran overview," 2010.

[6] L. Punnett and D. H. Wegman, "Work-related musculoskeletal disorders: the epidemiologic evidence and the debate," Journal of electromyography and kinesiology, vol. 14, no. 1, 2004, pp. 13-23.

[7] L. Peppoloni, A. Filippeschi, E. Ruffaldi, and C. Avizzano, "A novel wearable system for the online assessment of risk for biomechanical load in repetitive efforts," International Journal of Industrial Ergonomics, vol. 52, 2016, pp. 1-11.

[8] N. D. Nath, R. Akhavian, and A. H. Behzadan, "Ergonomic analysis of construction worker's body postures using wearable mobile sensors," Applied ergonomics, vol. 62, 2017, pp. 107-117.

[9] A. Ajoudani, A. M. Zanchettin, S. Ivaldi, A. Albu-Schäffer, K. Kosuge, and O. Khatib, "Progress and prospects of the human-robot collaboration," Autonomous Robots, vol. 42, no. 5, 2018, pp. 957-975.

[10] F. Romano, G. Nava, M. Azad, J. Čamernik, S. Dafarra, O. Dermy, C. Latella, M. Lazzaroni, R. Lober, M. Lorenzini et al., "The codyco project achievements and beyond: Toward human aware whole-body controllers for physical human robot interaction," IEEE Robotics and Automation Letters, vol. 3, no. 1, 2018, pp. 516-523.

[11] A. Billard, S. Calinon, R. Dillmann, and S. Schaal, "Robot programming by demonstration," in Springer handbook of robotics. Springer, 2008, pp. 1371-1394.
[12] A. Bicchi, M. A. Peshkin, and J. E. Colgate, "Safety for physical human-robot interaction," in Springer handbook of robotics. Springer, 2008, pp. 1335-1348.

[13] J. Fryman and B. Matthias, "Safety of industrial robots: From conventional to collaborative applications," in Robotics; Proceedings of ROBOTIK 2012; 7th German Conference on. VDE, 2012, pp. 1-5.

[14] M. Faber, J. Bützler, and C. M. Schlick, "Human-robot cooperation in future production systems: analysis of requirements for designing an ergonomic work system," Procedia Manufacturing, vol. 3, 2015, pp. $510-517$.

[15] J. Van der Vorm, L. OSullivan, R. Nugent, and M. de Looze, "Considerations for developing safety standards for industrial exoskeletons," 2015.

[16] ISO/TS 15066:2016, "Robots and robotic devices - collaborative robots," International Organization for Standardization, Geneva, Standard, 2016.

[17] T. Arnold and M. Scheutz, "Beyond moral dilemmas: Exploring the ethical landscape in hri," in Proceedings of the 2017 ACM/IEEE International Conference on Human-Robot Interaction, ser. HRI '17. ACM, 2017, pp. 445-452.

[18] P. Lin, K. Abney, and G. Bekey, "Robot ethics: Mapping the issues for a mechanized world," Artificial Intelligence, vol. 175, no. 5, 2011, pp. 942 - 949, special Review Issue. [Online]. Available: http://www.sciencedirect.com/science/article/pii/S0004370211000178

[19] D. Romero, J. Stahre, T. Wuest, O. Noran, P. Bernus, Å. Fast-Berglund, and D. Gorecky, "Towards an operator 4.0 typology: a human-centric perspective on the fourth industrial revolution technologies," in Proc. International Conference on Computers and Industrial Engineering (CIE46), 2016.

[20] S. Russell et al., "Ethics of artificial intelligence," Nature, vol. 521, no. 7553, 2015, pp. 415-416.

[21] "ROBOLAW deliverable 6.2 - guidelines on regulating robotics," URL: robolaw_d6.2_guidelinesregulatingrobotics_20140922.

[22] A. Grinbaum, R. Chatila, L. Devillers, J. G. Ganascia, C. Tessier, and M. Dauchet, "Ethics in robotics research: Cerna mission and context," IEEE Robotics Automation Magazine, vol. 24, no. 3, 2017, pp. 139145 .

[23] "Ethically aligned design v2 - ieee standard dev. document," URL: http://standards.ieee.org/develop/indconn/ec/ead_v2.pdf.

[24] G. Veruggio and F. Operto, "Roboethics: Social and ethical implications of robotics," in Springer handbook of robotics. Springer, 2008, pp. 1499-1524.

[25] A. Van Wynsberghe, "Service robots, care ethics, and design," Ethics and information technology, vol. 18, no. 4, 2016, pp. 311-321.

[26] F. Amigoni and V. Schiaffonati, "Ethics for robots as experimental technologies: Pairing anticipation with exploration to evaluate the social impact of robotics," IEEE Robotics \& Automation Magazine, vol. 25, no. 1, 2018, pp. 30-36.

[27] V. Villani, L. Sabattini, J. N. Czerniak, A. Mertens, and C. Fantuzzi, "Mate robots simplifying my work: The benefits and socioethical implications," IEEE Robotics \& Automation Magazine, vol. 25, no. 1, 2018, pp. 37-45.

[28] P. Lai, "The literature review of technology adoption models and theories for the novelty technology," JISTEM-Journal of Information Systems and Technology Management, vol. 14, no. 1, 2017, pp. 21-38.

[29] J. Schmidtler, K. Bengler, F. Dimeas, and A. Campeau-Lecours, "A questionnaire for the evaluation of physical assistive devices (quead): Testing usability and acceptance in physical human-robot interaction," in 2017 IEEE International Conference on Systems, Man, and Cybernetics (SMC), 2017, pp. 876-881.

[30] S. Ivaldi, L. Fritzsche, J. Babic, F. Stulp, M. Damsgaard, B. Graimann, G. Bellusci, and F. Nori, "Anticipatory models of human movements and dynamics: the roadmap of the andy project," in Proc. International Conf. on Digital Human Models (DHM), 2017.

[31] I. Gaudiello, E. Zibetti, S. Lefort, M. Chetouani, and S. Ivaldi, "Trust as indicator of robot functional and social acceptance. an experimental study on user conformation to icub answers," Computers in Human Behavior, vol. 61, 2016, pp. 633 - 655. [Online]. Available: http://www.sciencedirect.com/science/article/pii/S074756321630228X

[32] C. B. Frey and M. A. Osborne, "The future of employment: how susceptible are jobs to computerisation?" Technological Forecasting and Social Change, vol. 114, 2017, pp. 254-280.

[33] "2018 reform of EU data protection rules," URL: https: //ec.europa.eu/commission/priorities/justice-and-fundamental-rights/ data-protection/2018-reform-eu-data-protection-rules_en. 